\title{
Helicobacter pylori Negative
}

National Cancer Institute

\section{Source}

National Cancer Institute. Helicobacter pylori Negative. NCI Thesaurus. Code C146647.

An indication that Helicobacter pylori was not detected in a sample. 